\title{
Ionic Silver-Impregnated Sodium Carboxymethylcellulose Antimicrobial Dressing
}

National Cancer Institute

\section{Source}

National Cancer Institute. Ionic Silver-Impregnated Sodium Carboxymethylcellulose

Antimicrobial Dressing. NCI Thesaurus. Code C82679.

A textile fiber dressing composed of ionic silver-impregnated sodium

carboxymethylcellulose with potential wound-healing and antimicrobial activities. Ionic silver-impregnated sodium carboxymethylcellulose antimicrobial dressing inhibits microbial growth and promotes wound healing while protecting the wound site from external factors that may cause pain, promote infection, or slow the natural wound healing process. Ionic silver has a high affinity for neg atively charged side groups on microbial cell proteins. Upon binding, ionic silver alters the molecular structure of proteins with a role in normal microbial cell functions thereby interfering with cell wall synthesis, transcription, translation, electron transport across membranes and protein folding, resulting in microbial cell death. 